\title{
Study of Clinicobacteriological Profile of Neonatal Sepsis Patients Admitted In Tertiary Care Hospital in Telangana
}

Dr. Pooja Palla ${ }^{1^{*}}$, Dr. M. Alimelu ${ }^{2}$

${ }^{1}$ Assistant Professor Department of Microbiology, Osmania Medical College, Hyderabad India

${ }^{2}$ Professor Department of Pediatrics, Niloufer Hospital, Osmania Medical College, Hyderabad India

DOI: $10.36347 /$ sjams.2020.v08i11.011

| Received: 09.08.2020 | Accepted: 26.08.2020 | Published: 09.11.2020

*Corresponding author: Dr. Pooja Palla

Abstract

Original Research Article

Background: Septicemia in new born is of major public health concern, though recent medical advances have improved neonatal care, there are still many challenges remaining in the diagnosis and management of neonatal infection. Immature immune system and invasive life support make the premature neonates susceptible to infections. The diagnosis is complicated especially by the presence of noninfectious conditions. Objective: To study the Clinical and Bacteriological profile and antibiotic susceptibility pattern of septicemic neonates in the microbiology department, Niloufer hospital and find the significant risk factors leading to cause septicemia. Methods: Retrospective study was carried out in the Department of Microbiology at Niloufer Hospital, Red hills between January 2019 to Nov 2019.737 clinically suspected samples were included in the study, were processed. Identification and antibiogram of the isolates were done as per standard procedures. Clinical symptoms, Laboratory Parameters, Risk factors were statistical analysed, pvalue < 0.05 was considered significant. Results: Among 737 samples, 135 isolates identified and grouped.Gram positive organism 98 (72\%) out of which Coagulase Negative Staphylococcus 93(68.9\%). CoNS causing Proven Sepsis were 66 (48.9\%). Among Gram Negative Organism Klebsiella pneumonia (48.6\%) was commonest. Elevated CRP levels was significant to categorise CoNS isolate. Neutropenia and Thrombocytopeniawere significant in Gram negative sepsis. All the clinical symptoms and Risk factors were significant. Conclusion: Low birth weight and premature neonates are the greatest risk factors for the neonatal sepsis. Immature host defense mechanism and prolong use of CentralVenous catheters, mechanical ventilation, parenteral nutrition has led to the increase risk of CoNS infection in Late onset sepsis.By updating the Antibiotic policy can decrease the usage of Catheters and early shifting to enteral feeding can decrease the chance of late onset sepsis.

Keywords: Neonatal sepsis, immature immune system, elevated CRP.

Copyright $\left({ }_{0} 2020\right.$ The Author(s): This is an open-access article distributed under the terms of the Creative Commons Attribution 4.0 International License (CC BY-NC 4.0) which permits unrestricted use, distribution, and reproduction in any medium for non-commercial use provided the original author and source are credited.

\section{INTRODUCTION}

Sepsis in new born is of major public health concern. It is an extreme body response to invasion of blood stream by microorganism leading to systemic signs of infections. Newborn are at higher risk of developing sepsis leading to severe morbidity and mortality. India with nearly 6, 00,000new born deaths each year accounts for a quarter of the global burden of neonatal death (Unicef)[1]. Mortality due to septicemia has taken third portion after prematurity and perinatal asphyxia [2]. Sepsis occurring just after birth within $72 \mathrm{hrs}$ is termed as early onset due to maternal transmitted pathogens via genital tract during intrapartum period. Group B streptococci, Escherichia coli, Streptococcus viridians, Enterococci, Staphylococcus aureus, Pseudomonas aeruginosa, are responsible for sepsis in early hours of birth of child. Risk factors involved are maternal Group B
Streptococcal colonization, chorioamniotis, PROM, Preterm births (<37 wks), multiple gestation. Sepsis occurring after $72 \mathrm{hrs}$ of birth termed as late onset of sepsis attributed to horizontal transmission of pathogens. Acquired postnatally it can be community acquired or hospital acquired. Coagulase negative staphylococcus, staphylococcus aureus, candida albicans, E.coli, klebsiella pneumonia, Enterococci, pseudomonas aeruginosa are the pathoens isolated in late onset of sepsis. Prematurity, lowbirth weight, prolong indwelling catheter, invasive procedures, ventilator associated pneumonia, prolong usage of antibiotics being the risk factors.

Neonates become colonized by microorganisms present in environment with in first week of life. Sepsis caused by Coagulase negative staphylococcus (CoNS) is the major pathogen involved in LONS particularly at a low gestational age due to 
improper development of immune system. CoNS infection in newborn are rarely fatal, but they cause significant morbidity and multiresistance to antibodics .Being a common inhabitant of skin and mucous membrane, risk of infection due to coagulase negative staphylococcus increase with the use of central venous catheter, mechanical ventilation, parenteral nutrition and with other invasive procedures at Neonatal intensive care units. Presence of CoNS organism in neonatal sepsis is of dilemma as can reflect contamination rather than true bacteremia. Clinical presentation of sepsis in neonates is not specific unlike in older patients [7-10, 13]. Inorder to categorise the true cases of CoNS causing septicemia two positive blood cultures are required but in preterm neonates due to risk of multiple punctures, single positive blood culture and positive CRP (>10mg/l) considered as proven sepsis. Positive blood culture with negative CRP is considered as Contaminant [7]

WHO identified seven clinical signs- difficult feeding, convulsions, movement only when stimulated, respiratory rate $>60 / \mathrm{min}$, severe chest indrawing and axillary temperature $>37.5^{\circ} \mathrm{c}$ or $\left\langle 35.5^{\circ} \mathrm{c}\right.$ [3]. Perinatal antibiotic use, minimal blood volume sample for culture and repeated invasive procedures has made the diagnosis a big challenge [7].

Our aim is to study the clinicobacteriological profile of neonatal sepsis admitted at niloufer hospital, Redhills and to study the antibiotic resistance pattern to provide an effective early diagnosis for the clinicians to treat the patients.

\section{MeTHODS}

Retrospective study was conducted from January 2019 to November 2019 in the department of Microbiology, Niloufer hospital, Red hills. Sample size of 737 clinically suspected septicemic cases were included in the study. Neonates with congenital malformations, known chromosomal disorder were not included in the study. Premature neonates with low birth weight, risk factors like indwelling catheter, ventilation, parenteral nutrition developing sepsis after $72 \mathrm{hrs}$ of their birth, were included in the study.

\section{Sample collection}

$1 \mathrm{ml}$ of blood was collected in to $10 \mathrm{ml}$ of Tryptone soya broth and processed as per the protocol $[5,6]$ and incubated for one week at $37^{\circ} \mathrm{c}$ and was checked for bacterial growth daily. Subcultures were done on Blood agar, Mconkey Agar after 24 hrs of incubation if no growth occured on plates, subsequent cultures done on $3^{\text {rd }}$, 5th, $7^{\text {th }}$, day. The growth bacterium was identified by colony morphology, gram stain and standard biochemical tests $[5,6]$. The Antibiotic susceptibility testing was performed by Kirby bauer disc diffusion method for the bacterial isolates, as per clinical and laboratory standard institute guidelines
(CLSI). ATCC control strains were used accordingly as per standard procedures. Blood cultures positive for organism like corynebacterium, propionibacterium, penicillium and diphtheroids are considered as contaminants. Laboratory parameters like CRP, Hematologic indices (Thrombocytopenia, neutropenia) were also taken to distinguish CoNS isolation a pathogen or contaminant. The antibiotic discs (Himedia Co, Mumbai, India) and their concentrations per disc (ug) are: Ampicillin(10), Cefotaxime (30), Gentamicin (10), Amikacin (30), ciprofloxacin(5), vancomycin (30), piperacillin(100), Imepenem(10), Ceftazidime(30), Amoxycyllin (30), Erythromycin (15), Cefoxitin (30), Linezolid (30), Cotrimoxazole (30) ,Doxycyclin(10), Erythromycin (10), Teicoplanin (30ug ), Cefoperazon (30).

\section{Data Analysis}

All clinical symptoms, risk factors significant for causing sepsis were statistically analysed. The chi square test was used in assessing the association between variables.Statistical significance was defined as $\mathrm{p}<0.05$.

\section{RESULTS}

There were 737 preterm infants with less body weight, 135 showed pathogenic organisms. The incidence of neonatal sepsis was $18.3 \%$ among 737 blood samples enrolled in our study. Among the positive cases the bacteriological profile shows:

Table-1

\begin{tabular}{|l|l|}
\hline Gram positive organisms & $\mathbf{9 8}(\mathbf{7 2 \%})$ \\
\hline CONS & $93(68.9 \%)$ \\
\hline Staphylococcus aureus & $2(2 \%)$ \\
\hline Enterococcus faecalis & $3(3 \%)$ \\
\hline
\end{tabular}

Table-2

\begin{tabular}{|l|l|}
\hline Gram negative organisms & $\mathbf{3 7}(\mathbf{2 7 . 4 \%})$ \\
\hline Klebsiella pneumonia & $18(48.6 \%)$ \\
\hline Escherichia coli & $4(10.8 \%)$ \\
\hline Pseudomonas aeruginosa & $10(27 \%)$ \\
\hline Acenetobacter & $5(13.5 \%)$ \\
\hline
\end{tabular}

Among 93 CONS infection

Table-3

\begin{tabular}{|l|l|}
\hline Proven sepsis & Contaminants \\
\hline $66(48.9 \%)$ & $27(20 \%)$ \\
\hline
\end{tabular}

CoNS was the most common pathogen followed by Klebsiella pneumonia $18(13.33 \%)$. All the proven CoNS infection were sensitive to vancomycin, linezolid, Teicoplanin. 36(38.7\%) CoNS isolate were resistant to cefoxitin. All gram negative bacteria were sensitive to imipenem, Amikacin, Gentamicin and Meropenem. 
Table-4

\begin{tabular}{|l|l|l|l|}
\hline Clinical symptoms & Gram negative organism & Gram positiveorganism & P value \\
\hline Bradycardia & 30 & 55 & $<0.05$ \\
\hline Poor feeding & 35 & 38 & $<0.05$ \\
\hline Increased respiratory effort & 30 & 34 & $<0.05$ \\
\hline Tachycardia & 28 & 30 & $<0.05$ \\
\hline Fever & 14 & 27 & $>0.05$ \\
\hline Hypotension & 18 & 3 & $<0.05$ \\
\hline Hypothermia & 1 & 2 & $<0.05$ \\
\hline
\end{tabular}

Table-5

\begin{tabular}{|l|l|l|l|}
\hline Laboratory parameters & Gram negative organism & Gram positive oganism & P value \\
\hline CRP $>10 \mathrm{mg} / 1$ & 33 & 66 & $<0.05$ \\
\hline thrombocytopenia & 26 & 19 & $<0.05$ \\
\hline Neutopenia & 18 & 4 & $<0.05$ \\
\hline
\end{tabular}

Elevated CRP levels (73.3\%) were the most common laboratory findings among Gram positive organism causing LONS. Thrombocytopenia, Neutropenia was seen in Gram negative sepsis.
Presence of catheter at the time of sepsis and complete perenteral nutrition in preterm babies were identified as independent risk factor for CONS- LONS.

Table-6

\begin{tabular}{|l|l|l|l|}
\hline Risk fctors & Proven sepsis & Contaminants & P value \\
\hline Preterm $(<34$ wks $)$ & 60 & 12 & $<0.05$ \\
\hline Central line catheters & 60 & 14 & $<0.05$ \\
\hline Total Parenteral nutrition & 49 & 10 & $<0.05$ \\
\hline
\end{tabular}

\section{DISCUSSION}

Low birth weight $(<2000 \mathrm{gm})$ and Prematurity $(<34 w k s)$ form the greatest riskfactors to cause late onst sepsis because of compromised immunity, prolonged hyper alimentation, central line catherisation and mechanical ventilation .CoNS being ubiquitous commensals colonise the skin upto $99 \%$ of newborn by day 3 of life. As colonization precedes invasion, immature immune system lead to invasive CoNS infection [7-10,13]. Sepsis rate in our study is 18.3\%. Coagulase Negative Staphylococcus (CoNS) was the most causative organism in late onset sepsis, same observations also noted in W.H Lim et al. Elevated CRP levels being significant laboratory parameter in culture positive CoNS determine the actual proven sepsis. central line catheters, parenteral nutrition in premature neonates form the significant risk factors for proven CoNS late onset sepsis, similar outcome observed in CM Healy et al. el Manouniel Hassani et al. In our study 36 isolates of CoNS were resistant to cefoxitin and were sensitive to linezolid, vancomycin, and Teicoplanin. Widespread use of vancomycin may result in emergence of vancomycin resistance strain, using Ampicillin; oxacillin empirically in late onset sepsis is suggestive [10].

Klebsiella pneumonia was predominant among Gram Negative Organism similar to W.H. Lim et al. All the organisms were sensitive to Gentamicin, Amikacin which are used empirically along with Imipenem and meropenem. In our study neonates with thrombocytopenia and neutropenia developed sepsis caused by gram negative organisms.

Prolong use of catheters; parenteral nutrition was associated with increased risk of late onset sepsis, thus removal of catheters with enteral feeding should be initiated.

\section{Conclusion}

Advancements in neonatal intensive care units and routine antenatal checkups have decreased the incidence of inborn sepsis but preterm deliveries and low birth weight with low immune response has increased the incidence of late onset sepsis. Bacteriologic profile will help in updating the antibiotic policy to provide better treatment to the patients.

\section{REFERENCE}

1. Unicef 2018 global report on neonatal mortality rate. Every child Alive.2018.

2. Register general of India, Sample registration system (SRS) statistical report.

3. Shah BA, Padbury JF. Neonatal sepsis: an old problem with new insights. Virulence. 2014 Jan 1;5(1):170-8.

4. NICHID Neonatal network Survey;1998 to 2000.

5. Collee JG and Marr W. Culture of Bacteria. In: Mackie \& McCartney Practical Medical Microbiology, $14^{\text {th }}$ ed, Churcill Livingstone Elsevier. 2006; 113-129. 
6. Trevino S and Ross D. Bacteremia and sepsis. In: Text book of Diagnostic Microbiology, $3^{\text {rd }} \mathrm{ed}$, Mahon CR, Lehman D C, Manuselis G. 2007; 9951009.

7. Alonso Zea-Vera and Thresa J. Ochoa. Challenges in the diagnosis and management of Neonatal sepsis. Journal of tropical Pediatrics. 2015; 61: 113.

8. el Hassani SE, Berkhout DJ, Niemarkt HJ, Mann S, De Boode WP, Cossey V, Hulzebos CV, Van Kaam AH, Kramer BW, van Lingen RA, van Goudoever JB. Risk factors for late-onset sepsis in preterm infants: a multicenter case-control study. Neonatology. 2019;116(1):42-51.

9. Healy CM, Baker CJ, Palazzi DL, Campbell JR, Edwards MS. Distinguishing true coagulasenegative Staphylococcus infections from contaminants in the neonatal intensive care unit. Journal of perinatology. $2013 \mathrm{Jan} ; 33(1): 52-8$.
10. Lim WH, Lien R, Huang YC, Chiang MC, Fu RH, Chu SM, Hsu JF, Yang PH. Prevalence and pathogen distribution of neonatal sepsis among very-low-birth-weight infants. Pediatrics \& Neonatology. 2012 Aug 1;53(4):228-34.

11. Marchant EA, Boyce GK, Sadarangani M, Lavoie PM. Neonatal sepsis due to coagulase-negative staphylococci. Clinical and Developmental Immunology. 2013 Oct;2013.

12. Yadav NS, Sharma S, Chaudhary DK, Panthi P, Pokhrel P, Shrestha A, Mandal PK. Bacteriological profile of neonatal sepsis and antibiotic susceptibility pattern of isolates admitted at Kanti Children's Hospital, Kathmandu, Nepal. BMC research notes. 2018 Dec 1;11(1):301.

13. Craft a, Finer N. Nosocomial coagulase negative staphylococcal (CoNS) catheter-related sepsis in preterm infants: definition, diagnosis, prophylaxis, and prevention. Journal of Perinatology. 2001 Apr;21(3):186-92. 